\title{
Sermaye Yapısı Teorilerinin TCMB Sektör Bilançolarıyla Test Edilmesi: İmalat Sanayi Sektörü Üzerine Bir Panel Veri Analizi (2001-2015)
}

\author{
N. Savaș Demirci ${ }^{\mathrm{a}}$
}

\begin{abstract}
Öz: Günümüzde sermaye maliyetini minimize, işletme değerini de maksimize edecek optimal sermaye yapısına yönelik çeşitli teoriler tartışılmakla birlikte halen üzerinde fikir birliğine varılmış bir sermaye yapısı teorisi bulunmamaktadır. Başlıca sermaye yapısı teorilerinin ülkemizde ihracatın ana kaynağı konumunda bulunan ve ekonominin en stratejik sektörlerinden olan imalat sanayi sektöründe test edilmesi, sektörün borçlanma dinamikleri hakkında fikir verebilecektir. Çalışmada, Dengeleme ve Finansman Hiyerarşisi Teorileri kapsamında imalat sanayi sektöründe sermaye yapısının işletme düzeyindeki başlıca belirleyicileri, ülkemizdeki en kapsamlı reel sektör veri seti olan Türkiye Cumhuriyet Merkez Bankası (TCMB) sektör bilançoları kullanılarak 2001-2015 döneminde iki yönlü panel veri analizi ile araştırılmıştır. Ekonometrik analiz sonuçları; Türkiye imalat sanayi sektöründe kaldıraç oranının aktif kârlılık oranı, cari oran, maddi duran varlıkların toplam varlıklara oranı ve aktif büyüme oranından negatif, reel net satışlar tutarından pozitif olarak etkilendiğini ortaya koymaktadır. Çalışmanın sonuçlarına göre Türkiye imalat sanayi sektöründe borçlanma davranışları ağırlıkla Finansman Hiyerarşisi Teorisi kısmen de Dengeleme Teorisi tarafindan açıklanmaktadır.
\end{abstract}

Anahtar Sözcükler: Sermaye Yapısı Teorileri, İmalat Sanayi Sektörü, Panel Veri Analizi, TCMB Sektör Bilançoları

JEL Sınıflandırması: C58, G31, C33, L60

\section{Testing Capital Structure Theories with CBRT Sectoral Balance Sheets: A Panel Data Analysis on Manufacturing Industry Sector (2001-2015)}

\begin{abstract}
Nowadays however various theories for optimum capital structure that can minimize cost of capital and maximize value of firm are discussed, there is no universal capital structure theory agreed upon. Testing main capital structure theories in manufacturing industry sector which is the main source of exporting and one of the most strategic sectors of economy in our country may give opinion about debt dynamics of the sector. In this article, in the context of Trade-off and Pecking Order Theories, main determinants at firm level of capital structure have been studied with the Central Bank of the Republic of Turkey (CBRT) sectoral balance sheets which is the largest real sector data set in our country by using two-way panel data analysis in the period 2001-2015. Econometric analysis results show that in Turkish manufacturing industry sector leverage ratio is negatively affected by return on assets, current ratio, tangible assets to total assets ratio and assets growth rate and positively affected by real volume of net sales. According to the results of study debt behaviours in Turkish manufacturing industry sector are mostly explained by Pecking Order Theory and partly explained by Trade-off Theory.
\end{abstract}

Keywords: Capital Structure Theories, Manufacturing Industry Sector, Panel Data Analysis, CBRT Sectoral Balance Sheets

JEL Classification: C58, G31, C33, L60

asst. Prof., PhD., Kafkas University, Faculty of Economics and Administrative Sciences, Kars, Turkiye, n.savas.demirci@gmail.com 


\section{Giriş}

İşletmelerde finansal kaynakların planlanması ve kontrolü olarak tanımlanabilen finansal yönetim; genel olarak yatırım, finanslama ve kâr payı dağıtımı kararlarııı kapsar. Finansal yönetim bağlamında finans yöneticisinin en önemli görevlerinden biri de sermaye maliyetini minimize, işletme değerini de maksimize edecek sermaye yapısını oluşturmaya çalışmaktır. Genellikle uzun dönemli finansman kaynaklarının bileşimini ifade eden sermaye yapısı; kârlıık, büyüme firsatları, finansman stratejileri, yasal düzenlemeler, makroekonomik ortam vb. gibi işletme içi ve işletme dışı birçok faktörden etkilenebilmektedir. Optimal sermaye yapısına yönelik çeşitli teorilerin tartışıldı̆ı günümüzde halen üzerinde fikir birliğine varılmış ortak bir sermaye yapısı teorisi bulunmamakla beraber konuyla ilgili ampirik araştırmalar işletmelerin reel yatıımlarını finanse etmek için kullandıkları ve bilançoların pasifinde yer alan borç ve özkaynak kalemlerine yoğunlaşmaktadır.

Modern anlamda sermaye yapısı teorilerinin ilki Modigliani ve Miller'ın 1958 yılında yayımladıkları çalışmalarına dayanmaktadır. Sermaye piyasalarında tam rekabetin olduğu ve vergilerin bulunmadığı varsayımına dayanan Modigliani ve Miller'in geliştirdiği temel teoriye (M\&M Theory) göre işletmelerin ortalama sermaye maliyetleri ve piyasa değerleri sermaye yapılarından bağımsızdır, işletmelerin piyasa değerleri yatırımlardan beklenen getirilere (kârlara) ve bulundukları risk sınıfina ilişkin sermaye maliyetine diğer bir ifadeyle yatırımcıların bekledikleri getiri oranına (işletmenin yatırımlarından beklediği minimum getiri oranı) bağlıdır ve arbitraj olanakları işletmelerin piyasa değerlerini zaman içinde risk sınıfları paralelinde olması gereken gerçek düzeylerine çeker. Teoriye göre daha düşük maliyetli borç kullanım oranııı artması, işletmenin artan finansal riskine bağlı olarak özkaynak maliyetini de artırdığından ortalama sermaye maliyeti değişmez. Modigliani ve Miller 1963'te yayımladıkları çalışmalarında ise düzeltme yaparak borcun sağladığı vergi kalkanını da teorilerine dahil etmişler ve borç kullanımının işletmenin değerini artırabileceğini vurgulamışlardır.

Başlıca sermaye yapısı teorileri arasında yer alan Dengeleme ve Finansman Hiyerarşisi Teorileri uzun yıllardan beri yoğun olarak tartş̧ımakla beraber günümüzde de halen popülerliklerini korumaktadır. Robichek ve Myers (1966), Kraus ve Litzenberger (1973) ve Scott'ın (1976) ilk savunucuları arasında yer aldığı Dengeleme Teorisine (Trade-off Theory) göre işletmelerin piyasa değerlerini maksimize edecek sermaye yapıları; borcun vergi kalkanının bugünkü değeri ile borçlanmanın beraberinde getirdiği ve Jensen ve Meckling'in (1976) değindiği temsil maliyetlerini de içeren finansal maliyetlerin bugünkü değeri arasındaki denge tarafindan belirlenir. Myers (1984), teori kapsamında her işletmenin piyasa değerini maksimize edecek kendine özgü bir optimal sermaye yapısı bulunduğunu ve bu bağlamda işletmelerin hedef borç oranlarına sahip olduklarını fakat ayarlama maliyetleri nedeniyle bu hedeften sapabildiklerini belirtmiştir.

Donaldson'ın (1961) çalışmasına dayanan Finansman Hiyerarşisi Teorisi de (Pecking Order Theory) temelde işletmelerin piyasa değerlerini maksimize etmek amacıyla finansman ihtiyaçları için öncelikle iç kaynaklara yöneldiklerini savunmaktadır. Myers (1984), yönetim ve çıkarım giderleri gerektirmeyen ucuz iç kaynakların yetmediği durumlarda işletmelerin daha düşük maliyet nedeniyle ilk önce borçlandıklarını en son olarak da dış kaynaklardan sağlanan özkaynağa yöneldiklerini ve bu nedenle optimal bir sermaye yapısının bulunmadığını öne sürmektedir. Aynı yazara göre işlem maliyetlerinin daha yüksek olması, kâr payı ödemelerinin faiz ödemelerinin aksine vergiden indirilememesi ve kreditörlerin varlıklar ve gelirler üzerinde hisse senedi sahiplerine göre daha öncelikli konumda bulunmaları; dış kaynaklı özkaynağı daha maliyetli hale getirmektedir. Myers ve Majluf da (1984) dış kaynaklar açısından borç finansmanının göreceli daha az risk taşıdığını, sermaye piyasalarından sağlanan özkaynak finansmanında ilk olarak Akerlof'un (1970) limon piyasası teorisiyle incelediği asimetrik bilgi problemlerinin daha yoğun yaşandığını ve ilişkili maliyetlerin daha yüksek olduğunu savunmaktadırlar. İşletme değerini maksimize edecek optimal sermaye yapısına yönelik arayışlar devam etmekle beraber Baker ve Wurgler'in (2002) ortaya koydukları ve işletmelerin sermaye yapılarını piyasadaki dinamik hisse senedi fiyat değişimlerine göre oluşturduklarını savunan Piyasa Zamanlama Teorisi de (Market Timing Theory) popülerliğini korumaktadır. 
Dünya genelinde sanayi sektörünün en büyük alt sektörü konumunda bulunan imalat sanayinde, piyasa değerini maksimize edebilme etkisine sahip olduğu yaygın olarak kabul edilen borç kullanma düzeyinin hangi faktörlerden etkilendiğinin tespiti ve sonuçların modern sermaye yapısı teorileri çerçevesinde analiz edilerek yorumlanması, ekonomilerde finansman tercihleri ve davranışlarının analiz edilmesi açısından önem taşımaktadır. İmalat sanayi sektörü, sürdürülebilir ekonomik büyüme ve kalkınmaya katkı noktasında uzun yıllardan beri kilit sektör olma özelliğini korumaktadır. Bugünün birçok gelişmiş ülkesi; Sanayi Devrimi'nden 1960'ların ortasına dek yüksek verimlilikle çalışan imalat sanayi sektörleri sayesinde hızlı bir şekilde sanayileşmiş, yüksek ekonomik büyüme oranları yakalamış ve günümüz modern ekonomilerinin temellerini atmıştır (Naude ve Szirmai, 2012: 2). Bununla birlikte Kaldor'un (1967) imalat sanayinin ekonomik büyümenin itici gücü olduğunu savunan görüşü günümüzde artk bilgi ve iletişim teknolojilerine dayalı hizmetler sektörünün ağırlıkta olduğu gelişmiş ülkelerde geçerli olmamakla beraber imalat sanayinin özellikle gelişmiş ülkelerde, ekonomik büyüme ve kalkınmanın stratejik kaynağı olmaya devam ettiği söylenebilir. İmalat sanayi sektörü, günümüzde dünya genelinde olduğu gibi Türkiye'de de ekonomi içindeki payı daralmakla birlikte, ekonomik hayata yüksek düzeyde katkı sağlamaktadır. 2000 yılında ülkemiz ekonomisi içindeki payı \%22'den 2014 yılında \%18'e düşen imalat sanayi sektörü, mal ihracatının 2014'te yaklaşık 5'te 4'ünü toplam istihdamın ise 2015 verilerine göre yaklaşık 5'te 1'ini karşılamaktadır (WTO, 2015: 91; tuik.gov.tr).

Ülkemizdeki işletmelerin optimal borç düzeylerinde faaliyet göstermeleri sadece kendi sermaye maliyetlerini minimize etmekle kalmayacak, yatırımların sayısını ve kârılığını hızlı bir şekilde artırarak ülke ekonomisine de ek katkı sağlayabilecektir. Il gili amaçlara ulaşmak için uygulanacak işletme düzeyindeki finansman stratejilerinin etkinliği açısından borç düzeylerini etkileyen değişkenlerin tespit edilmesi gerekmektedir. Bu bağlamda en kapsamlı reel sektör veri seti konumunda bulunan Türkiye Cumhuriyet Merkez Bankası (TCMB) sektör bilançolarından yararlanmasıyla diğer benzer çalışmalardan ayrılan bu çalışma; ülkemiz ekonomisinin sürükleyici sektörü konumunda bulunan imalat sanayi sektöründe, Dengeleme ve Finansman Hiyerarşisi Teorileri paralelinde sermaye yapısı göstergesi kaldıraç oranlarının hangi değişkenlerden anlamlı olarak etkilendiğini panel veri analiziyle ortaya koymayı hedeflemektedir. Bu amaçla öncelikle literatür araştrılımakta ve daha sonra da 2001-2015 yıllarını kapsayan döneme ait ekonometrik analiz sonuçlarına yer verilmektedir.

\section{Literatür}

Türkiye'de en geniş reel sektör veri setini sağlayan TCMB sektör bilançoları verileriyle imalat sanayi sektöründe sermaye yapılarını etkileyen değişkenleri zaman serileri analizi ile inceleyen tek bir çalışma olmakla birlikte konuyla ilgili diğer çalışmalarda çoğunlukla borsaya kote işletmelerin verileri kullanılmıştır. Bu araştırma, imalat sanayi sektörünün alt sektörlerine ait toplulaştrılmış verilerini dikkate almasına ek olarak farklı değişkenleri ve farklı dönem verilerini içermesiyle işletme düzeyinde verileri dikkate alan fakat alt sektörlerin toplu verilerini kullanmayan Köksal ve Orman'ın 2015 tarihli çalışmasından farklılık göstermektedir.

Sayılgan, Karabacak ve Küçükkocaoğlu (2006); Borsa İstanbul'a kote 123 imalat sanayi şirketinin 19932002 yıllarına ait verilerinden yararlanarak kurdukları dinamik panel veri modeliyle sermaye yapısını etkileyen faktörleri araştırmışlardır. Analiz sonuçlarına göre borç/özkaynak oranı ile temsil edilen sermaye yapısı; büyüklük ve varlıkların büyüme oranından pozitif, kârlılık, borç dışı vergi kalkanı, maddi duran varlıkların büyüme oranı ve varlık yapısından ise negatif olarak etkilenmektedir.

Yıldız, Yalama ve Sevil (2009); Borsa İstanbul'a kayıtlı imalat sanayi şirketlerinin 1998-2006 dönemine ait verilerinin kullanarak Dengeleme ve Finansman Hiyerarşisi Teorilerini test etmek için üç farklı panel regresyon modeli kurmuşlardır. Model tahmin sonuçları; sermaye yapısı ile büyüme oranı ve büyüklük arasında pozitif, sermaye yapısı ile kârlılık arasında ise negatif ilişkileri ve veri setinde yer alan işletmelerde sermaye yapısının ağırlıkla Finansman Hiyerarşisi Teorisinin tarafindan açıklandığını ortaya koymuştur.

Ata ve Ağ (2010), hisseleri Borsa İstanbul'da işlem gören 42 imalat sanayi şirketinde 2003-2007 döneminde firma karakteristiğinin sermaye yapısı üzerindeki etkisini panel veri analiziyle araştırdıkları çalışmalarında sermaye yapısını temsilen yabancı kaynakların varlıklara oranını kullanmış ve büyüme oranı, 
faiz karşılama oranı ve likiditenin sermaye yapısını negatif, büyüklüğün ise pozitif olarak etkilediği belirtmişlerdir.

Köksal ve Orman (2015), TCMB sektör bilançolarını oluşturan 6000'inin üzerinde imalat sanayi işletmesinin 1996-2009 dönemine ait verilerini panel veri analizi ile inceledikleri çalışmalarında kaldıraç oranının kârlılık, varlık yapısı, Gayri Safi Yurtiçi Hasıla (GSYiH) büyüme oranı ve işletme riskinden negatif; işletme büyüklüğü, enflasyon oranı, vergi yükü, sektörün ortalama kaldıraç oranı ve sermaye akımlarından pozitif olarak etkilendiği sonuçlarına ulaşmışlardır. Yazarlar makroekonomik değişkenler de dikkate alındığında sektördeki işletmelerin sermaye yapısı dinamiklerinin özellikle Dengeleme Teorisi tarafindan açıklandığını vurgulamışlardır.

Abdioğlu ve Deniz (2015), Borsa İstanbul'a kote 188 imalat sanayi işletmesinin 2009-2013 yıllarına ait verilerini panel veri analizinde kullandıkları çalışmalarında toplam borçların toplam varlıklara oranı ile ifade edilen kaldıraç oranını etkileyen değişkenleri incelemiş ve bağımlı değişkenin kârlılık, likidite, maddi duran varlıklar oranından negatif, satışlardaki dalgalanmalardan ise pozitif olarak etkilendiği sonucuna ulaşmış ve sonuçların ağırlıkla Finansman Hiyerarşisi Teorisini desteklediğini ortaya koymuşlardır.

Acaravcı (2015), sermaye yapısı belirleyicilerini araştırdığı ve Borsa İstanbul'a kote 79 imalat sanayi şirketinin 1993-2010 dönemine ilişkin verilerinden yararlandığı çalışmasında borçların varlıklara oranının bağımlı değişken olarak kullanıldığı panel regresyon modeli kurmuş ve kaldıraç oranı ile büyüklük, kârııık ve varlık yapısı arasında negatif ilişkilere ulaşmıştır.

Burucu ve Öndeş (2016), sermaye yapısını etkileyen faktörleri dinamik panel veri analizi ile inceledikleri çalışmalarında, hisseleri Borsa İstanbul'da işlem gören 50 imalat sanayi şirketinin 1990-2014 dönemine ilişkin verilerini kullanmışlardır. Çalışmada bağımlı değişken kaldıraç oranı üzerinde büyüklüğün, maddi duran varlıklar oranının, kârlılığın ve likiditenin negatif, büyüme oranı ve büyüme firsatlarının ise kaldıraç oranı üzerinde pozitif etkisi olduğunu ortaya koymuşlar ve analiz sonuçlarının kısa ve uzun vadede Finansman Hiyerarşisi Teorisiyle büyük ölçüde uyumlu olduğunu vurgulamışlardır.

Türkiye dışında imalat sanayi sektöründe kaldıraç oranının hangi değişkenlerden etkilendiğini ortaya koymayı amaçlayan yazarlardan Voulgaris, Asteriou ve Agiomirgianakis (2002), Yunanistan'da 75 büyük ölçekli imalat sanayi işletmesinin 1988-1996 dönemine ilişkin verilerinden yararlandıkları çalışmalarında kaldıraç oranının bağımlı değişken olarak kullanıldığı panel regresyon modeli kurmuşlar ve borç düzeyinin büyüme firsatları ve varlık devir hızından pozitif; net kâr marjından ise negatif olarak etkilendiği sonucuna ulaştıklarını belirtmişlerdir.

Kim, Heshmati ve Aoun (2006); 1985-2002 yıllarını kapsayan ve Kore'de 617 imalat sanayi işletmesinde kaldıraç oranını etkileyen değişkenleri panel veri modelleriyle inceledikleri çalışmalarında kaldıraç oranı ile büyüme oranı, işletme riski, kârlılık ve borç dışı vergi kalkanı arasında negatif, kaldıraç oranı ile işletme büyüklüğü arasında da pozitif ilişkiler tespit etmişlerdir.

Achy (2009); işletmelerin borçlanma davranışlarını araştırdığı çalışmasında, Fas'ta borsaya kote olmayan 550 imalat sanayi işletmesinin 1998-2003 dönemine ait verilerini kullanmıştır. Çalışmada bağımlı değişken kaldıraç oranı ile varlık yapısı, işletme büyüklüğü ve kârııık arasında negatif; kaldıraç oranı ile büyüme firsatları arasında anlamlı pozitif ilişkiler tespit etmiş ve sektördeki işletmelerin Finansman Hiyerarşisi Teorisine uygun finansman kararları aldıklarını belirtmiştir.

Degryse, De Goeij ve Kappert (2009); 2003-2005 dönemini yıllık verilerle inceledikleri ve Hollanda imalat sanayi sektöründe faaliyet gösteren küçük ve orta büyüklükteki işletmelerin (KOBi) verilerini panel veri analizinde kullandıkları araştırmalarında işletme büyüklüğü, varlık yapısı, net borç oranı, maddi olmayan varlıklar oranı, büyüme firsatları ve borç dışı vergi kalkanının kaldıraç oranına pozitif, kârııı̆ın ise bağımlı değişkene negatif etkide bulunduğu yönünde sonuçlara ulaşmışlardır.

Sheikh ve Wang (2011), hisseleri Karaçi Borsası'nda işlem gören 160 imalat sanayi şirketinin 20032007 yılları arasındaki verilerini kullanarak, kaldıraç oranının bağımlı değişken olarak yer aldığı panel veri modelleri kurmuşlardır. Çalışmada kaldıraç oranı ile kârııık, varlık yapısı, likidite ve risk arasında negatif; 
kaldıraç oranı ve şirket büyüklüğü arasında da pozitif ilişkilerin olduğu tespit edilmiştir. Çalışmada söz konusu şirketlerin borçlanma davranışlarının büyük oranda Finansman Hiyerarşisi Teorisi ile açıklanabileceğine vurgu yapılmıştır.

Cortez ve Susanto (2012), Tokyo Borsası'na kote 21 imalat sanayi şirketinin verileriyle borç/özkaynak oranının bağımlı değişken olarak yer aldığı panel veri modeli kurmuşlar ve ilgili oranın varlık yapısından pozitif, kârlılık ve borç dışı vergi kalkanından ise negatif olarak etkilendiğini belirtmişlerdir.

\section{Ekonometrik Analiz}

\subsection{Veri Seti ve Değişkenler}

İmalat sanayi sektöründe Dengeleme ve Finansman Hiyerarşisi Teorileri çerçevesinde alt sektörlerde sermaye yapısını etkileyen işletme düzeyindeki başlıca değişkenleri tespit etmeyi amaçlayan bu ekonometrik analizde, TCMB tarafindan hazırlanan sektör bilançoları verilerinden yararlanılmıştır. TCMB, reel sektörde faaliyet gösteren yaklaşık on bin işletmeye ait sektör bazında ayrıntılı finansal bilgileri 1996 yılından itibaren düzenli olarak her yıl kamuoyuyla paylaşmaktadır. TCMB'nin verilerini kullandığı işletmeler yıldan yıla farklılaşabilmekle beraber üç yıllık sürekli bilanço ve gelir tablosu bulunan işletmelere ait finansal veriler toplulaştrılarak sektörel finansal tablolar hazırlanmaktadır. ilgili alt sektörde faaliyet gösteren işletmelerin bilanço ve gelir tablosu kalemlerine ilişkin tutarlar toplanarak alt sektörlerin toplu bilançoları ve gelir tabloları oluşturulmaktadır. 2015'teki çalışmada bilgileri yer alan 9.341 işletmenin toplam çalışan sayısı 2 milyona yaklaşmaktadır. TCMB sektör bilançoları; ülkemizde reel sektöre ilişkin verileri içeren en geniş veri seti konumunda bulunmaktadır.

Çalışmanın veri setini oluşturan TCMB sektör bilançoları kapsamında süreklilik arz etmeyen imalat sanayi alt sektörleri veri setinden çıkarılmış, bazı alt sektörlerdeki veri kısıtları nedeniyle ilgili sektörlerden birkaçı birleştirilmiş ve birleştirilen sektörlere ilişkin oran ve büyüklükler tarafimızdan hesaplanmıştır. Ekonometrik analize konu olan 12 imalat sanayi alt sektörüne ait 2001-2015 yılları arasında 15 döneme ilişkin yıllık veriler TCMB'nin web sitesinden alınmıştır. Bu bağlamda örneğin bir alt sektördeki 100 işletmenin bilanço veya gelir tablosu kalemleri toplanarak tek bir finansal tablo oluşturulmaktadır. Bu nedenle 100 işletmenin verisi kullanılmasına rağmen tek bir gözlem ortaya çıkmaktadır. Bu şekilde 12 alt sektörün 15 döneme ait finansal tablolarından elde edilen oranların gözlem sayıları 180 olmuştur. Veri setinin 2001 yılından başlamasının nedeni ise; ülkemizde 2000 ve 2001 yıllarında yaşanan finansal krizlerinden sonra imalat sanayi işletmelerinin yoğun olarak kullandıkları kredilerin ${ }^{1}$ kaynağı olan bankacılık sisteminde yapılan köklü reformlar ve sağlanan göreceli makroekonomik istikrardır. 2015 itibariyle verilerinden yararlanılan 2.874 işletmenin imalat sanayi alt sektörlerine göre yüzdesel dağılımı aşağıdaki gibidir:

Tablo 1. Veri Setindeki İşletmelerin Sektörel Dağılımı (\%)

\begin{tabular}{|l|c|}
\hline Sektör & \% pay \\
\hline Gıda ürünleri ve içecek sanayi & 19 \\
\hline Tekstil ürünleri sanayi & 16 \\
\hline Metalik olmayan mineral ürünler sanayi & 11 \\
\hline Ana metal ve fabrikasyon metal ürünleri sanayi & 9 \\
\hline Giyim eşyaları sanayi & 8 \\
\hline Kauçuk ve plastik ürünler sanayi & 8 \\
\hline Makine ve ekipman sanayi & 8 \\
\hline Motorlu araçlar ve diğer ulaşım araçları sanayi & 7 \\
\hline Kimya ürünleri ve eczacılık sanayi & 6 \\
\hline Kâğıt ürünleri ve basım sanayi & 4 \\
\hline Ağaç ve ağaç ürünleri sanayi & 2 \\
\hline Deri ve ilgili ürünler sanayi & 2 \\
\hline Toplam & $\mathbf{\% 1 0 0}$ \\
\hline
\end{tabular}

Kaynak: www.tcmb.gov.tr 
Yaklaşık üç bin işletmenin verileriyle oluşturulan sektörel bilanço ve gelir tabloları aracılığıyla imalat sanayi sektöründe sermaye yapısını etkileyen faktörleri tespit etmeyi amaçlayan bu ekonometrik analizde kullanılmak üzere, daha önceki benzer çalışmalarda sıklıkla yer alan 1 bağımlı değişken ve 6 bağımsız değişken seçilmiştir. Sermaye yapısını etkilemesi beklenen bağımsız değişkenler; kârlılığı, likiditeyi, varlık yapısını, büyüklüğü, büyüme firsatlarını ve borç dışı vergi kalkanını temsilen çalışmaya dahil edilmiştir. Çalışmada kullanılan ve defter değerleri üzerinden hesaplanan bağımlı ve bağımsız değişkenler şunlardır:

\section{Bağımlı değissken:}

Sermaye Yapısı: Kaldıraç Oranı (LEVERAGE): Sermaye yapısını temsil eden kaldıraç oranı; Drobetz ve Wanzenried (2006), Serrasqueiro, Armada ve Nunes (2011) ve Cole'un (2012) sermaye yapısını inceleyen çalışmalarında olduğu gibi borcun geniş tanımı dikkate alınarak yabancı kaynakların varlıklara oranı olarak hesaplanmıştır:

$$
\text { Kaldıraç Oranı }=\frac{\text { Yabancı Kaynaklar }}{\text { Toplam Varlıklar }}
$$

\section{Bağımsız değişkenler:}

Kârlılık: Aktif Kârlıık Oranı (PROF): Kârlııı̆ı ifade eden aktif kârlııık oranı; Song (2005), Niu (2008) ve Margaritis ve Psillaki'nin (2010) sermaye yapısını konu eden çalışmalarında kullandıkları şekilde faiz ve vergi öncesi kârın (FVÖK) toplam varlıklara oranlanması ile bulunmuştur:

$$
\text { Aktif Kârlılık Oranı }=\frac{\text { FVÖK (Vergiden Önceki Kâr + Fin. Gid. })}{\text { Toplam Varlıklar }}
$$

Dengeleme Teorisi (+): Dengeleme teorisi kapsamında Jensen (1986), borç kullanımını yöneticileri disipline edici bir araç olarak tanımlamış ve özellikle kurumsal yönetimin etkin olduğu kârlı işletmelerin daha yüksek kaldıraç oranlarına sahip olacaklarını belirtmiştir.

Finansman Hiyerarşisi Teorisi (-): Finansman Hiyerarşisi Teorisi çerçevesinde Myers ve Majluf'a (1984) göre kârlı faaliyet gösteren işletmeler finansman ihtiyaçları için ilk olarak iç kaynaklara yöneleceklerinden borç kullanım düzeyleri düşecektir.

Likidite: Cari Oran (LIQ): Net çalışma sermayesi düzeyini ortaya koymak için Niu (2008), Sarlija ve Harc (2012) ve Kajananthan ve Achchuthan'ın (2013) sermaye yapısını etkileyen değişkenleri araştırdıkları çalışmalarında kullandıkları cari oran tercih edilmiştir:

$$
\text { Cari Oran }=\frac{\text { Dönen Varlıklar }}{\text { Kısa Vadeli Yabancı Kaynaklar }}
$$

Dengeleme Teorisi (+): Harris ve Raviv (1990), işletmeler yeni borç kullanmak için kreditörlere başvurduklarında kredi vereceklerin dikkate aldıkları kriterlerin başında geri ödemelerin zamanında yapılabilmesini sağlayacak likidite düzeyi geldiğinden dolayı yüksek cari orana sahip işletmelerin daha yüksek kaldıraç oranlarına sahip olabileceklerini belirtmişlerdir.

Finansman Hiyerarşisi Teorisi (-): Niu (2008), likidite düzeyinin iç kaynakların büyüklüğünün de bir göstergesi olduğundan yeterli likiditeye sahip işletmelerin daha az borç kullanacaklarını ifade etmiştir.

Varlık Yapısı: Maddi Duran Varlıklar(Net)/Varlıklar Oranı (TANG): Maddilik göstergesi olarak dikkate alınan oran; Lemmon ve Zender (2002), Hovakimian, Hovakimian ve Tehranian (2004) ve Frank ve Goyal'ın (2009) sermaye yapısına ilişkin yaptıkları çalışmalarda kullandıkları şekilde net maddi duran varlıkların toplam varlıklara oranı olarak analize dahil edilmiştir:

Dengeleme Teorisi (+): Frank ve Goyal (2009); Dengeleme Teorisine göre maddi duran varlıkların kredi anlaşmalarında teminat olarak kullanılabilmesinin, bu varlıkların likiditasyon değerinin göreceli yüksek 
oluşunun ve borç kullanımına ilişkin temsil maliyetlerinin maddi duran varlık oranı yüksek işletmelerde daha düşük olmasının işletmelere daha düşük faiz oranlarıyla borç kullanma firsatı tanıdığını vurgulamışlardır.

Finansman Hiyerarşisi Teorisi (-): Harris ve Raviv (1991) teori kapsamında maddi duran varlıklarla ilişkili düşük düzeydeki bilgi asimetrisinin özkaynak finansman maliyetini düşürdüğünü, borç finansman maliyetini ise artırdığını savunmuştur.

Büyüklük: Net Satşlar (SIZE): İşletme büyüklüğü; sermaye yapısını inceleyen Song (2005) ve Margaritis ve Psillaki'nin (2010) çalışmalarında tercih ettikleri net satışlar tutarı ile ifade edilmiştir. Net satş̧lar tüketici fiyat endeksi (TÜFE) $(2003=100)$ kullanılarak reel hale getirilmiş ve ilgili tutarların doğal logaritmaları hesaplanmıştır.

Dengeleme Teorisi (+): Frank ve Goyal (2009); Dengeleme Teorisine göre büyük işletmelerin faaliyetlerini çeşitlendirmeleri nedeniyle iflas riskleri düşük olduğundan, kredi piyasalarına daha kolay ulaşabildiklerinden ve borç kullanımına ilişkin daha düşük temsil maliyetleriyle karşılaştıklarından dolayı işletme büyüklüğü artthkça kaldıraç oranının da artacağını belirtmişlerdir.

Finansman Hiyerarşisi Teorisi (-): Teori bağlamında Fama ve Jensen'e (1983) göre işletme büyüklüğü hisse senedi yatırımcıları için bilgi sağladığından dolayı işletmeler büyüdükçe özkaynak finansmanı kaynaklı bilgi asimetrisi maliyetleri düşerek özkaynak finansman düzeyi artabilecek, borç kullanım düzeyi de azalarak kaldıraç oranı düşebilecektir.

Büyüme Fırsatları: Aktif Büyüme Oranı (GROWTH): Büyüme firsatları; Fama ve French (2002), Song (2005) ve Serrasqueiro, Armada ve Nunes'in (2011) sermaye yapısı teorilerini araştırdıkları analizlerinde kullandıkları şekilde toplam varlık tutarlarındaki reel değişim oranı olarak dikkate alınmıştır:

$$
\text { Aktif Büyüme Oranı }=\frac{(\mathrm{t} \text { yılında varlık toplamı })-(\mathrm{t}-1 \text { yılında varlık toplamı })}{(\mathrm{t}-1 \text { ylında varlık toplamı })}
$$

Dengeleme Teorisi (-): Fama ve French'e (2002) göre Dengeleme Teorisi kaldıraç oranı ve büyüme firsatları arasında negatif ilişki olduğunu öne sürmektedir. Aynı yazarlar büyüme firsatlarına sahip işletmelerin borç sahipleriyle hisse sahipleri arasındaki temsil sorunundan kaynaklanabilecek gereğinden daha az yatırım yapma durumundan kaçınmak için özkaynak finansmanını daha çok tercih ettiklerini ve serbest nakit akışı sorunlarını kontrol etmek için daha az borca ihtiyaç duyduklarını savunmuşlardır.

Finansman Hiyerarşisi Teorisi (+): Teori paralelinde Frank ve Goyal'a (2005) göre hızlı büyüyen işletmelerin zaman içinde borç kullanımları ve oranları da artacaktır.

Borç Dışı Vergi Kalkanı: Amortismanlar/Varlıklar Oranı (NDTS): Borç dışı vergi kalkanı; Wu (2007) ve Ramaratnam ve Jayaraman'ın (2013) çalışmalarında kullandıkları şekilde stok değişken olarak amortisman giderlerindeki ve tükenme paylarındaki net değişimi gösteren toplam birikmiş amortismanların toplam varlıklara oranı olarak hesaplanmıştır.

Dengeleme Teorisi (-): Dengeleme Teorisinin borç dışı vergi kalkanı ve kaldıraç oranı arasında negatif ilişkinin varlı̆ıını savunduğunu belirten Fama ve French'e (2002) göre birikmiş amortisman oranı yüksek işletmeler vergi yüklerini azaltmakta ve faiz ödemeleri aracılı̆̆ıyla ödenecek vergiyi azaltıcı etkiye sahip borç kullanımına daha az ihtiyaç duymaktadır.

Finansman Hiyerarşisi Teorisi (x): Finansman Hiyerarşisi Teorisi, borç dışı vergi kalkanı ve sermaye yapısı arasındaki ilişkiye dair bilgi içermemektedir.

Panel veri setine ilişkin tanımlayıcı istatistikler aşağıdaki gibidir: 
Tablo 2. Değişkenlere İlişkin Tanımlayıcı İstatistikler

\begin{tabular}{|c|c|c|c|c|c|c|c|}
\hline & $\begin{array}{c}\text { LEVERAGE } \\
(\%)\end{array}$ & PROF (\%) & LIQ (\%) & $\begin{array}{c}\text { TANG } \\
(\%)\end{array}$ & SIZE & $\begin{array}{c}\text { GROWTH } \\
(\%)\end{array}$ & NDTS (\%) \\
\hline Ortalama & 56,36775 & 9,600227 & 147,9472 & 30,51852 & 15,80693 & 6,236771 & 46,26452 \\
\hline Medyan & 56,44919 & 8,974742 & 147,2320 & 30,02140 & 16,05268 & 4,986626 & 42,57572 \\
\hline Maksimum & 80,98570 & 26,55783 & 199,7378 & 47,96032 & 17,76530 & 96,61080 & 102,1029 \\
\hline Minimum & 30,12545 & $-0,456287$ & 81,12874 & 12,78846 & 13,25744 & $-41,27021$ & 13,32093 \\
\hline Std. Sapma & 8,678507 & 3,556095 & 18,59368 & 7,326749 & 1,109658 & 16,27774 & 20,20420 \\
\hline $\begin{array}{c}\text { Gözlem } \\
\text { Sayıs }\end{array}$ & 180 & 180 & 180 & 180 & 180 & 180 & 180 \\
\hline
\end{tabular}

Tanımlayıcı istatistiklere göre veri setine dahil imalat sanayi sektöründeki işletmeler varlıkların ortalama \%56'sını yabancı kaynaklar, ortalama \%44'ünü ise özkaynaklar ile finanse etmektedir. Imalat sanayi sektöründeki işletmeler genel olarak varlıklarını kârlı kullanmakta ve 1 birim varlık başına yaklaşık 0,1 birim faiz ve vergi öncesi kâr ortaya koymaktadır. Dönen varlıklar kısa vadeli yabancı kaynakların yaklaşık 1,5 katıyken aktiflerin yaklaşık \%31'ini maddi duran varlıklar oluşturmaktadır. Varlıklardaki reel büyüme oranı yıllık yaklaşık \%6 olmakla beraber büyüme oranı değişkeninin yüksek standart sapmaya sahip olması reel anlamda küçülen işletmelerin varlığını da göstermektedir. Yine borç dışı vergi kalkanını temsil eden birikmiş amortismanların toplam varlıklara oranı ise $\% 46$ 'dır.

\subsection{Yöntem ve Analiz Sonuçları}

Yatay kesit verileri ile zaman serilerinin birleştirilmesiyle ortaya çıkan panel veri; göreceli daha doğru parametre tahminleri sağladığından, gözlemlenemeyen değişkenlerin daha kolay kontrol edilmesine imkân verdiğinden, değişkenlerin dinamik yapısını ortaya çıkardığından ve benzer özelliklere sahip birimlere ilişkin daha uygun analiz sonuçlarına ulaşılmasına yardımcı olduğundan dolayı yatay kesit verilerine ve zaman serilerine birçok açıdan üstünlük sağlar (Hsiao, 2007: 2-6).

Panel veri analizinde, sabit etkiler (fixed effects) veya tesadüfi etkiler (random effects) modellerinden yararlanılır. Sabit etkiler modeli aşağıdaki gibi ifade edilir (Gujarati, 2003: 642):

$$
Y_{i t}=\alpha_{i}+\beta_{2} X_{2 i t}+\varepsilon_{i t}(\text { Tek yönlü sabit etkiler modeli) }
$$

Sabit etkiler modelinde $Y_{i t}$ bağımlı değişkeni, $X_{2 i t}$ bağımsız değişkeni, $\alpha_{i}$ birimden birime değişebilen sabiti, $\beta_{2}$ bağımsız değişkenin eğim katsayısını, $\varepsilon_{i t}$ hata terimini ifade ederken; i modeldeki birimlerden her birini, $\mathrm{t}$ ise zamanı göstermektedir. Sabit etkiler modelinde yatay kesit birimleri arasındaki spesifik bireysel özellikleri temsil eden sabit, birimler arasında farklılık gösterebilirken; her birimin sabiti zamana bağlı olarak değişmez. Sabit etkiler modelinde eğim katsayılarının yatay kesit ve zaman boyutuna göre değişmediği kabul edilir. Bu haliyle sadece birim etkisini dikkate alan ve tek yönlü (sabit birim etkileri modeli) olan modele zaman

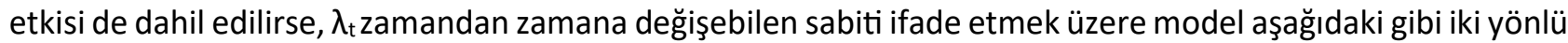
sabit etkiler modeline dönüşür (Gujarati, 2003: 642-644):

$$
Y_{i t}=\alpha_{i}+\beta_{2} X_{2 i t}+\varepsilon_{i t}+\lambda_{t}(\text { iki yönlü sabit etkiler modeli) }
$$

Panel veri analizinde yararlanılan diğer bir model ise tesadüfi etkiler modelidir. Bu model aşağıdaki gibi ifade edilir (Gujarati, 2003: 647):

$$
Y_{i t}=\alpha+\beta_{2} X_{2 i t}+w_{i t}\left(\mu_{i}+\varepsilon_{i t}\right) \text { (Tek yönlü tesadüfi etkiler modeli) }
$$

Tesadüfi etkiler modelinde birimlerin ortak sabitleri olduğu kabul edilir ve birimlere özgü farklılıklar hata terimleri ile ifade edilir. $\mu_{i}$ birimlere özgü sıfir ortalamalı ve sabit varyanslı gözlemlenemeyen tesadüfi hata terimiyken, $\varepsilon_{i t}$ zaman serisi ile yatay kesitin birleşimi sonucu ortaya çıkan hata terimi, $w_{i t}$ ise bileşik hata 
terimidir. Tesadüfi etkiler modelinde $\alpha$ yatay kesit sabitlerinin ortalamasını, $\mu_{\mathrm{i}}$ ise birimlere ilişkin sabitlerin ortalama sabitten tesadüfi sapmasını ifade eder (Gujarati, 2003: 647-648). Bu haliyle sadece birim etkisini dikkate alan ve tek yönlü (tesadüfi birim etkileri modeli) olan modele $\lambda_{t}$ ile ifade edilen gözlemlenemeyen zaman etkisi de dahil edilirse, model aşağıdaki gibi iki yönlü tesadüfi etkiler modeline dönüşür (Baltagi, 2005: 33-35):

$$
Y_{i t}=\alpha+\beta_{2} X_{2 i t}+w_{i t}\left(\mu_{i}+\varepsilon_{i t}+\lambda_{t}\right) \text { (iki yönlü tesadüfi etkiler modeli) }
$$

Çalışmada sermaye yapısını temsil eden kaldıraç oranının bağımlı değişken olarak yer alacağı panel regresyon modeli kurulmadan önce modeldeki bağımsız değişkenler arasında doğrusal bir ilişki mevcut olduğunda ortaya çıkan ve parametre tahminlerinde hatalı sonuçlara yol açabilen çoklu bağlantı (multicollinearity) sorunun olup olmadığına bakılması gerekmektedir. Açıklayıcı değişkenler arasında çoklu bağlantı sorununun olup olmadı̆̆ı, bağımsız değişkenlerin varyans şişirme faktörlerine (Variance Inflation Factors-VIF) bakılarak tespit edilebilir. il gili değerleri 10' un üstünde olan bağımsız değişkenlerin yer aldığı modellerde çoklu bağlantı sorunu ortaya çıkmaktadır (Wooldridge, 2012: 95-98). Varyans şişirme faktör değerleri² PROF, LIQ, TANG, SIZE, GROWTH ve NDTS değişkenleri için sırasıyla 1,08, 1,43,1,53,1,28, 1,11 ve 2,06 bulunmuştur ve bu durum da bağımsız değişkenler arasında çoklu bağlantı sorununun olmadığını göstermektedir.

Panel veri analizi, yatay kesit ve zaman serileri analizlerine karşı çeşitli açılardan üstün olmakla birlikte zaman boyutuna da sahip olduğundan zaman serilerinde karşılaşılan sorunları da içerebilmektedir. Bu bağlamda panel veri setinde durağan dışılıkla karşılaşılabilmektedir. Ortalaması, varyansı ve otokovaryansı zamandan bağımsız olarak sabit kalan bir zaman serisi durağan olarak diğer bir ifadeyle birim kök taşımadığı kabul edilir. Durağanlık koşullarını sağlamayan seriler ise birim köke sahiptir (Asteriou ve Hall, 2007: 231). Granger ve Newbold (1974), finansal ve iktisadi analizlere durağan olmayan verilerin dahil edilmesinin sahte regresyon problemine neden olabileceğini savunmuşlardır. Sahte regresyondan elde edilen sonuçlara ilişkin model parametrelerini yorumlamak anlamsız hale gelmekte ve yorumlar yanlış değerlendirmelere neden olabilmektedir. Bu nedenle ekonometrik analizlerde sahte regresyonla karşılaşmamak için serilerin durağanlıkları incelenmelidir. Literatürde panel veri setlerine yönelik birden fazla birim kök testi geliştirilmiştir. Panel birim kök testlerinden tekil testler ve ortak birim kök testleri, verilerin durağanlığının tespiti için sıklıkla tercih edilmektedir. En yaygın kullanılan ortak panel birim kök testleri Levin, Lin, Chu (2002) ve Breitung (2000), tekil panel birim kök testleri ise Maddala ve Wu (1999) ve Choi (2001) tarafindan geliştirilen Fisher tabanlı Artırılmış Dickey-Fuller (ADF) ve Phillips-Perron (PP) testleri ve Im, Pesaran, Shin (2003) testidir. Serilerde birim kökün varlığını araştırmak amacıyla, Levin, Lin, Chu (LLC) ve Artırımış DickeyFuller (ADF) panel birim kök testleri kullanılmıştr. Her iki test için de aşağıdaki hipotezler kurulmuştur:

\section{$\mathrm{H}_{0}$ : Seri durağan değildir (Birim kök içerir)}

\section{$\mathrm{H}_{1}$ : Seri durağandır (Birim kök içermez)}

Optimal gecikme düzeyi için Akaike kriteri ve Newey-West bant genişliği için Bartlett Kernel'in kullanıldığı ve maksimum gecikme uzunluğunun 1 olarak belirlendiği birim kök testlerinin sonuçları düzeyde sabitli ve sabitli-trendli olarak aşağıdaki gibidir³:

Tablo 3. Birim Kök Test Sonuçları

\begin{tabular}{|c|c|c|c|c|}
\hline \multirow{2}{*}{} & \multicolumn{2}{|c|}{ LLC (p-değeri) } & \multicolumn{2}{c|}{ ADF (p-değeri) } \\
\cline { 2 - 5 } & Sabitli & Sabitli-Trendli & Sabitli & Sabitli-Trendli \\
\hline LEVERAGE & 0,0045 & 0,0000 & 0,0211 & 0,0050 \\
\hline PROF & 0,0000 & 0,0000 & 0,0000 & 0,0000 \\
\hline LIQ & 0,0000 & 0,0000 & 0,0000 & 0,0000 \\
\hline TANG & 0,0357 & 0,0000 & 0,0951 & 0,0003 \\
\hline SIZE & 0,0001 & 0,0183 & 0,0060 & 0,0679 \\
\hline GROWTH & 0,0000 & 0,0000 & 0,0000 & 0,0000 \\
\hline NDTS & 0,0686 & 0,0000 & 0,3447 & 0,4660 \\
\hline
\end{tabular}


Veri setinde LEVERAGE, PROF, LIQ, TANG, SIZE ve GROWTH değişkenleri \%10 anlamlılık seviyesinde düzeyde durağanken, düzeyde durağan olmayan NDTS değişkeni 1. farkı alınarak birim kökten arındırılmıştır. Modellerde durağan serilerin kullanılması gereğinden hareketle tahmin edilen panel veri modeline LEVERAGE, PROF, LIQ, TANG, SIZE ve GROWTH değişkenlerinin düzey değerleri; NDTS değişkeninin ise durağan 1. farkı dahil edilmiştir.

Panel veri analizinde uygun regresyon modelini tespit etmek için çeşitli testlerden yararlanılmaktadır. Bu testlerden ilki panel veri setinin yatay kesit ve zaman boyutunu ihmal eden ve klasik En Küçük Kareler (EKK) yöntemi ile tahmin edilen havuzlanmış regresyon (pooled regression) ile sabit etkiler regresyon modeli arasında tercih yapmak için kullanılan ve $\mathrm{F}$ istatistiğine dayanan olasılık oran (likelihood ratio) testidir. Testte $\mathrm{H}_{0}$ sıfir hipotezleri, sırasıyla "birimlere bağlı sabit etki yoktur", "zamanlara bağlı sabit etki yoktur" ve "hem birimlere hem de zamanlara bağlı sabit etki yoktur" şeklinde kurulur (Greene, 2003: 289; Brooks, 2008: 508). Panel veri modeli için elde edilen olasılık oran test sonuçları aşağıdaki gibidir:

Tablo 4. Olasılık Oran Test Sonuçları

\begin{tabular}{|c|c|c|c|}
\hline & istatistik & $\begin{array}{c}\text { Serbestlik } \\
\text { derecesi }\end{array}$ & $\begin{array}{c}p- \\
\text { değeri }\end{array}$ \\
\hline$F_{\text {birim }}$ & 21,897854 & 11,137 & 0,0000 \\
\hline$F_{\text {zaman }}$ & 15,344089 & 13,137 & 0,0000 \\
\hline$F_{\text {birim-zaman }}$ & 20,628884 & 24,137 & 0,0000 \\
\hline
\end{tabular}

Olasılık oran test sonuçlarına göre $\mathrm{H}_{0}$ sıfır hipotezlerinin \%1 anlamlılık düzeyinde reddedilmesi; sabit etkiler modelinin havuzlanmış regresyon modeline tercih edilmesi ve ayrıca sabit etkiler modelinin tahmin edilmesi durumunda sabit etkilerin hem birim hem de zaman boyutunda dikkate alınması gerektiğini işaret etmektedir. Lagrange Çarpanı (Lagrange Multiplier) testi ise panel veri setinin yatay kesit ve zaman boyutunu ihmal eden ve klasik En Küçük Kareler (EKK) yöntemi ile tahmin edilen havuzlanmış regresyon ile tesadüfi etkiler regresyon modeli arasında tercih yapmak için kullanılır. Testte tesadüfi etkilerin birim boyutunda, zaman boyutunda ve hem birim hem de zaman boyutunda anlamsızlığı $\mathrm{H}_{0}$ ile ifade edilir (Torres-Reyna, 2007: 32). Tesadüfi etkilerin anlamlılığı için çift kuyruklu Breusch-Pagan (1980) ve tek kuyruklu Honda (1985) testlerinden yararlanılmıştır:

Tablo 5. Lagrange Çarpanı Test Sonuçları

\begin{tabular}{|l|l|l|c|}
\hline & Birim & Zaman & Birim-Zaman \\
\hline Breusch-Pagan & 367,9058 & 29,28602 & 397,1918 \\
Test istatistiği (p-değeri) & $(0,0000)$ & $(0,0000)$ & $(0,0000)$ \\
\hline Honda & 19,18087 & 5,411656 & 17,38954 \\
Test istatistiği (p-değeri) & $(0,0000)$ & $(0,0000)$ & $(0,0000)$ \\
\hline
\end{tabular}

Her iki testin sonuçlarına göre $\mathrm{H}_{0}$ sıfir hipotezlerinin \%1 anlamlılık düzeyinde kabul edilmemesi; tesadüfi etkiler modelinin havuzlanmış regresyon modeline tercih edilmesi ve ayrıca tesadüfi etkiler modelinin seçilmesi durumunda tesadüfi etkilerin hem birim hem de zaman boyutunda dikkate alınması gerektiğini ifade etmektedir. Panel veri modellerinin seçiminde kullanılan bir diğer test olan Hausman (1978) testinin sonucuna göre de sabit etkiler modelinin mi yoksa tesadüfi etkiler modelinin mi daha etkin olduğuna karar verilir. Testte $\mathrm{H}_{0}$ sıfır hipotezi, "tesadüfi etkiler ve açıklayıcı değişkenler arasında korelasyon yoktur" şeklinde ifade edilir. Hausman testi sonuçları aşağıdaki gibidir: 
N. S. Demirci

Tablo 6. Hausman Testi Sonuçları

\begin{tabular}{|c|c|c|c|}
\hline & Ki-kare istatistiği & Serbestlik Derecesi & p-değeri \\
\hline Birim & 26,306542 & 6 & 0,0002 \\
\hline Zaman & 50,849910 & 6 & 0,0000 \\
\hline
\end{tabular}

Hausman testi sonuçlarına göre $\% 1$ anlamlılık düzeyinde $\mathrm{H}_{0}$ sıfir hipotezi hem birim hem de zaman boyutunda reddedilmiştir. Sıfir hipotezinin kabul edilmemesi, tesadüfi etkiler ve açıklayıcı değişkenler arasında korelasyonun bulunduğunu ve bu durumda birim ve zaman boyutlarında sabit etkilerin dikkate alınacağı modelin tahmin edilmesinin daha etkin olacağını göstermektedir. Olasılık oran sonuçları da dikkate alındığında tahmin edilen sabit etkiler modelinde hem birim etkisi hem de zaman etkisi dikkate alınmıştır.

Zaman serileri ve yatay kesit analizlerinde olduğu gibi panel veri analizlerinde de otokorelasyon (autocorrelation) ve hata terimlerinin varyansının sabit olmadığı durumda ortaya çıkan değişen varyans (heteroscedasticity) sorunlarıyla karşılaşılabilmektedir (Gujarati, 2003: 68-70). Model tahmininde otokorelasyon ve değişen varyans sorunlarının ${ }^{4}$ varlığında robust (dirençli) standart hatalara ve doğru sonuçlara ulaşmak amacıyla white period tahmincisi kullanılmıştır (Reed ve Ye, 2011: 989). Dengeli panel veri setine ilişkin iki yönlü sabit etkiler modeli ve model tahmin sonuçları aşağıdaki gibidir ${ }^{5}$ :

LEVERAGE $_{i t}=\alpha_{i}+\beta_{1}$ PROF $_{i t}+\beta_{2}$ LIQ $_{i t}+\beta_{3}$ TANG $_{i t}+\beta_{4}$ SIZE $_{i t}+\beta_{5}$ GROWTH $_{i t}+\beta_{6} N$ TSS $_{i t}+\varepsilon_{i t}+\lambda_{t}$

Tablo 7. İki Yönlü Sabit Etkiler Modeli Tahmin Sonuçları ${ }^{6}$

\begin{tabular}{|c|c|c|c|}
\hline & \multicolumn{3}{|c|}{ Bağımlı Değişken: LEVERAGE } \\
\hline Bağımsız Değişkenler & Katsayı & Standart hata & p-değeri \\
\hline PROF & $-0.176111^{* * *}$ & 0.102367 & 0.0876 \\
\hline LIQ & $-0.191083^{*}$ & 0.040212 & 0.0000 \\
\hline TANG & $-0.233469^{* *}$ & 0.108665 & 0.0334 \\
\hline SIZE & $6.708516^{*}$ & 2.023588 & 0.0012 \\
\hline GROWTH & $-0.034285^{* * *}$ & 0.018562 & 0.0669 \\
\hline NDTS & 0.031668 & 0.021567 & 0.1443 \\
\hline Gözlem sayısı: $168^{7}$ & F-istatistiği (p-değeri): $34,077(0,0000)$ & Düz. $\mathrm{R}^{2}: 0,855951$ \\
\hline
\end{tabular}

$*, * *$ ve $* * *$ sırasıyla $\% 1, \% 5$ ve $\% 10$ anlamlılık düzeyini ifade etmektedir

Tablo 8. Model Tahmin Sonuçlarının Sermaye Yapısı Teorileriyle Karşılaştırılması

\begin{tabular}{|l|c|c|c|}
\hline Değişkenler & Analiz Sonuçları & Dengeleme Teorisi & Finansman Hiyerarşisi Teorisi \\
\hline Kârlıık (PROF) & - & + & $-\mathbf{v}$ \\
\hline Likidite (LIQ) & - & + & $-\mathbf{V}$ \\
\hline Varlık Yapısı (TANG) & - & + & $-\mathbf{V}$ \\
\hline Büyüklük (SIZE) & $\mathbf{+}$ & $\mathbf{+}$ & - \\
\hline Büyüme Fırsatları (GROWTH) & - & $-\mathbf{V}$ & $\mathbf{+}$ \\
\hline Borç Dışı Vergi Kalkanı (NDTS) & $\mathbf{x}$ & - & $\mathbf{x}$ \\
\hline
\end{tabular}

Kaldıraç oranının bağımlı değişken olarak kullanıldığı model tahmininin F-istatistiğine bakıldığında \%1 anlamlılık düzeyinde genel olarak anlamlı olduğu ve bağımlı değişkendeki değişimin yaklaşık \%86'sının bağımsız değişkenler tarafindan açıklandığı görülmektedir. Model tahmin sonuçlarına göre NDTS hariç tüm bağımsız değişkenlerin katsayılarının anlamsız olduğunu ifade eden $\mathrm{H}_{0}$ sıfir hipotezleri \%10 anlamlılık düzeyinde reddedilmiştir. Değişkenlerden PROF, LIQ, TANG ve GROWTH kaldıraç oranını negatif ve anlamlı 
olarak etkilerken; SIZE değişkeni ise kaldıraç oranını pozitif ve anlamlı olarak etkilemektedir. Model tahmin sonuçlarının Dengeleme ve Finansman Hiyerarşisi Teorileriyle karşılaştırılması ise şu şekildedir:

Ülkemizde imalat sanayi sektöründe kârlılığın arttkça varlıkların yabancı kaynaklarla finanse edilme oranının azalması, yüksek likidite düzeyine sahip sektörlerde daha az yabancı kaynak kullanılması, maddi duran varlıkların toplam varlıklar içindeki payının artmasıyla kaldıraç oranının düşmesi ve borç dışı vergi kalkanı ile kaldıraç oranı arasındaki ilişiksizlik; Finansman Hiyerarşisi Teorisini desteklemektedir. Diğer taraftan reel net satış tutarı açısından büyük olan imalat sanayi sektörlerinin daha fazla yabancı kaynak kullanması ve hızlı bir şekilde büyüyen sektörlerin daha az yabancı kaynağa ihtiyaç duyması da Dengeleme Teorisinin öne sürdüğü görüşlerle uyumluluk göstermektedir. Model tahmin sonuçlarından hareketle imalat sanayi işletmelerinin sermaye yapısı tercihlerinde genel olarak ağırlıkla Finansman Hiyerarşisi Teorisine kısmen de Dengeleme Teorisine uygun hareket ettikleri söylenebilir. Bu bağlamda her iki teori de sektördeki işletmelerin sermaye yapısı davranışlarını tam olarak açıklayamamaktadır.

\section{Sonuç}

Çalışmada ülkemizdeki en kapsamlı reel sektör veri setini içeren Türkiye Cumhuriyet Merkez Bankası (TCMB) sektör bilançolarının 2001-2015 dönemi yıllık verilerinden yararlanılarak ülkemiz ekonomisinin sürükleyici ve stratejik sektörü konumunda bulunan imalat sanayi sektöründe, Dengeleme ve Finansman Hiyerarşisi Teorileri çerçevesinde kaldıraç oranı ile temsil edilen sermaye yapılarının literatürde sıklıkla tercih edilen hangi açıklayıcı değişkenlerden anlamlı olarak etkilendiğini panel veri analiziyle araştırmak amaçlanmıştır. Bağımsız değişkenlerden aktif kârlılık oranı kârlıı̆ğı, cari oran likiditeyi, maddi duran varlıkların varlıklara oranı varlık yapısını, reel net satışlar işletme büyüklüğünü, reel varlıkların değişim oranı büyüme fırsatlarını ve birikmiş amortismanların varılılara oranı da borç dışı vergi kalkanını temsilen analize dahil edilmiştir. Çalışmada kullanılan ve birim köke sahip borç dılı vergi kalkanı serisi fark alma işlemine tabi tutularak durağanlaştrıııı̧ ve iki yönlü sabit etkiler modeli otokorelasyon ve değişen varyans sorunlarından arındırılarak tahmin edilmiştir.

Model tahmin sonuçları; imalat sanayi sektöründe kaldıraç oranının aktif kârlılık oranından, cari orandan, maddi duran varlıklar ve büyüme oranlarından negatif, işletme büyüklüğünden de pozitif olarak anlamlı bir şekilde etkilendiğini göstermektedir. Sektörde kârlılık oranları arttıç̧a, likidite düzeyleri yükseldikçe, maddi duran varlıklar toplam aktif içinde daha fazla pay aldıkça, işletmeler özelinde sektörler daha hızlı büyüdükçe borç (yabancı kaynak) kullanım oranı düşmekteyken işletmeler net satışlarını artırdıkça borç kullanım oranı yükselmektedir. Analiz sonuçları, ülkemizde imalat sanayi sektöründe borç kullanım tercihlerinin ağılıkla Finansman Hiyerarşisi Teorisi kısmen de Dengeleme Teorisi tarafindan açıklandığını ortaya koymaktadır.

Çalışmanın sonuçlarına göre ülkemiz imalat sanayi sektöründe büyük oranda, işletmelerin finansman için öncelikle iç kaynaklara yöneldiklerini ve iç kaynakların yetmediği durumlarda da borçlandıklarını savunan Finansman Hiyerarşisi Teorisinin geçerli olması; Yıldız, Yalama ve Sevil (2009), Abdioğlu ve Deniz (2015) ve Burucu ve Öndeş'in (2016) ulaştkları sonuçları desteklemektedir. Diğer taraftan analiz sonuçları, Fas ve Pakistan gibi gelişmekte olan ülke imalat sanayi sektörlerinde sermaye yapısı kararlarının ağırlıkla Finansman Hiyerarşisi Teorisi tarafindan açıklandığı sonucuna ulaşan Achy (2009) ve Sheik ve Wang'ın (2011) çalışmalarıyla da aynı yöndedir. Türkiye'nin de içinde yer aldığı gelişmekte olan ülkelerde benzer sonuçlara ulaşılmasında, bu ülkelerde finansal sistemlerin göreceli daha az gelişmiş olması ve dış kaynaklara erişimde zorluklar yaşanması nedenleriyle işletmelerin iç kaynaklara yönelmek zorunda kalmalarının da etkili olduğu söylenebilir. Çalışmadan elde edilen sonuçlar, özellikle göreceli istikrarlı makroekonomik ortamın hüküm sürdüğü 2000 sonrası Türkiye ekonomisinde dayandığı geniş veri setiyle imalat sanayi sektörünün sermaye yapısı analizlerine ışık tutabilecektir. 


\section{Son Notlar}

1. 2015 TCMB sektörel bilanço verilerine göre imalat sanayi sektöründe yabancı kaynakların yaklaşık \%45'ini banka kredileri oluşturmaktadır

2. Varyans şişirme faktör değerleri, Stata 12 ekonometrik analiz programı kullanılarak hesaplanmıştır

3. Panel birim kök testleri Eviews 9 ekonometrik analiz programı kullanılarak yapılmıştır, çalışmada aksi belitilmedikçe yapılan diğer analizlerde de bu program kullanılmıştır.

4. Stata 12 ekonometrik analiz programı kullanılarak Wald değişen varyans ve Wooldridge otokorelasyon testleri yapılmış ve değişen varyans ve otokorelasyonun varlığı tespit edilmiştir (Her iki test için de $p$-değeri=0,0000).

5. LEVERAGE, PROF, LIQ, GROWTH, TANG ve NDTS değişkenleri \% olarak analize dahil edilmiştir.

6. Birimlere ve zamanlara göre değiştiğinden, sabitlere $\left(\alpha_{i}\right.$ ve $\left.\lambda_{t}\right)$ tahmin sonuçlarında yer verilmemiştir.

7. Tanımlayıcı istatistiklerde gözlem sayısı 180 olmasına rağmen, durağanlık analizi sonucu düzeyde durağan olamayan NDTS değişkeninin 1. farkı alınarak durağanlaştırıldığından 1 dönem kaybı yaşanmış ve tahmin edilen modelde gözlem sayısı 168 olmuştur.

\section{Kaynaklar}

Abdioğlu, N., \& Deniz, D. (2015). Borsa İstanbul'da işlem gören imalat sanayi şirketlerinin sermaye yapılarının firmaya özgü belirleyicileri. Sosyoekonomi, 23(26), 195-213.

Acaravcl, S.K. (2015). The determinants of capital structure: Evidence from the Turkish manufacturing sector. International Journal of Economics and Financial Isuues, 5(1), 158-171.

Achy, L. (2009). Corporate capital structure choices in MENA: Empirical evidence from non-listed firms in Morocco. Middle East Development Journal, 1(2), 255-273.

Akerlof, G.A. (1970). The market for lemons: Quality uncertainty and the market mechanism. The Quarterly Journal of Economics, 84(3), 488-500.

Asteriou, D., \& Hall, S.G. (2007). Applied econometrics. New York: Palgrave Macmillan.

Ata, H.A., \& Ağ, Y. (2010). Firma karakteristiğinin sermaye yapısı üzerindeki etkisi. Ekonometri ve istatistik Dergisi, 11, 45-60.

Baker, M., \& Wurgler, J. (2002). Market timing and capital structure. The Journal of Finance, LVII(1), 1-32.

Baltagi, B.H. (2005). Econometric analysis of panel data. Wiltshire: John Wiley\&Sons.

Breitung, J. (2000). The local power of some unit root tests for panel data. (Ed.) B.H. Baltagi, Nonstationary panels, panel cointegration, and dynamic panels (ss. 161-177). Amsterdam: Elsevier.

Breusch, T.S., \& Pagan, A.R. (1980). The lagrange multiplier test and its applications to model specification in econometrics. The Review of Economic Studies, 47(1), 239-253

Brooks, C. (2008). Introductory econometrics for finance. New York: Cambridge University Press.

Burucu, H., \& Öndeş, T. (2016). Türk imalat sanayi firmalarının sermaye yapısını etkileyen faktörlerin analizi. Karatekin Üniversitesi i.i.B.F. Dergisi, 6(1), 201-225.

Choi, I. (2001). Unit root tests for panel data. Journal of International Money and Finance, 20(2), 249-272.

Cole, R.A. (2012). What do we know about the capital structure of privately held firms?: Evidence from the surveys of small business finance. Financial Management, 45(Winter), 777-813.

Cortez, M.A., \& Susanto, S. (2012). The determinants of corporate capital structure: Evidence from Japanese manufacturing companies. Journal of International Business Research, 11(3), 121-135.

Degryse, H., De Goeij, P., \& Kappert, P. (2009). The impact of firm and industry chracteristics on small firms' capital structure: Evidence from Dutch panel data (CentER Discussion Paper No. 2009-21), https://pure.uvt.nl/ws/files/1090501/2009-03.pdf (27.3.2017).

Donaldson, G. (1961). Corporate debt capacity; A study of corporate debt policy and the determination of corporate debt capacity. Boston: Harvard University.

Drobetz, W., \& Wanzenried, G. (2006). What determines the speed of adjustment to the target capital structure?. Applied Financial Economics, 16(13), 941-958. 
Fama, E.F., \& French, K.R. (2002). Testing trade-off and pecking order predictions about dividends and debt. The Review of Financial Studies, 15(1), 1-33.

Fama, E.F., \& Jensen, M.C. (1983). Agency problems and residual claims. Journal of Law and Economics, 26(2), 327-349.

Frank, M.Z., \& Goyal, V.K. (2005). Trade-off and pecking order theories of debt. http://www.tc.umn.edu/ murra280/WorkingPapers/Survey.pdf (25.12.2016).

Frank, M.Z., \& Goyal, V.K. (2009). Capital structure decisions: Which factors are reliably important?. Financial Management, 38(1), 1-37.

Granger, C.W.J., \& Newbold, P. (1974). Spurious regression in econometrics. Journal of Econometrics, 2(1974), 111-120.

Greene, W.H. (2003). Econometric analysis. New Jersey: Pearson Education.

Gujarati, D.N. (2003). Basic econometrics. New York: McGraw-Hill.

Harris, M., \& Raviv, A. (1990). Capital structure and the informational role of debt. The Journal of Finance, 45(2), 321349.

Harris, M., \& Raviv, A. (1991). The theory of capital structure. The Journal of Finance, XLVI(1), 297-355.

Hausman A.J. (1978). Specification tests in econometrics. Econometrica, 46(6), 1251-1271.

Honda, Y. (1985). Testing the error components model with non-normal distribution. Review of Economic Studies, 52(4), 681-690.

Hovakimian, A., Hovakimian, G., \& Tehranian, H. (2004). Determinants of target capital structure: The case of dual debt and equity issues. Journal of Financial Economics, 71(3), 517-540.

Hsiao, C. (2007). Panel data analysis-advantages and challenges. TEST, 16(1), 1-22.

Im, K.S., Pesaran, M.H., \& Shin, Y. (2003). Testing for unit roots in heterogeneous panels. Journal of Econometrics, 115(1), 53-74.

Jensen, M.C. (1986). Agency costs of free cash flow, corporate finance, and takeovers. The American Economic Review, 76(2), 323-329.

Jensen, M.C., \& Meckling, W.H. (1976). Theory of the firm: Managerial behavior, agency costs and ownership structure. Journal of Financial Economics, 3(4), 305-360.

Kajananthan, R., \& Achchuthan, S. (2013). Liquidity and capital structure: Special reference to Sri Lanka Telecom Plc. Advances in Management\&Applied Economics, 3(5), 89-99.

Kaldor, N. (1967). Strategic factors in economic development. New York: Ithaca.

Kim, H., Heshmati, A., \& Aoun, D. (2006). Dynamics of capital structure: The case of Korean listed manufacturing companies. Asian Economic Journal, 20(3), 275-302.

Köksal, B., \& Orman, C. (2015). Determinants of capital structure: Evidence from a major developing country. Small Business Economics, 44(2), 255-282.

Kraus, A., \& Litzenberger, R.H. (1973). A state-preference model of optimal financial leverage. Journal of Finance, 28(4), 911-922.

Lemmon, M.L., \& Zender, J.F. (2002). Debt capacity and tests of capital structure theories (Working paper University of Utah). http://citeseerx.ist.psu.edu/viewdoc/download?doi=10.1.1.488.325\&rep=rep1\&type=pdf (11.11.2016).

Levin, A., Lin, C.F., \& Chu, C. J. (2002). Unit root tests in panel data: Asymptotic and finite-sample properties. Journal of Econometrics, 108(1): 1-24.

Maddala, G.S., \& Wu, S. (1999). A comparative study of unit root tests with panel data and a new simple test. Oxford Bulletin of Economics and Statistics, 61(S1), 631-652.

Margaritis, D., \& Psillaki, M. (2010). Capital structure, equity ownership and firm performance. Journal of Banking\&Finance, 34(3), 621-632.

Mayer, C., \& Sussman, O. (2003). A new test of capital structure (OFRC Working paper series). http://www.nccrfinrisk.uzh.ch/media/pdf/Mayer-Sussman.pdf (8.12.2016).

Modigliani, F., \& Miller, M.H. (1958). The cost of capital, corporation finance and the theory of investment. The American Economic Review, XLVIII(3), 261-297.

Modigliani, F., \& Miller, M.H. (1963). Corporate income taxes and the cost of capital: A correction. The American Economic Review, 53(3), 433-443.

Myers, S.C. (1984). The capital structure puzzle. The Journal of Finance, 39(3), 574-592. 
Myers, S.C., \& Majluf, N.S. (1984). Corporate financing and investment decisions: When firms have information that investors do not have. Journal of Financial Economics, 13(1984), 187-221.

Naude, W., \& Szirmai, A. (2012). The importance of manufacturing in economic development: Past, present and future perspectives (Working paper series/United Nations University, UNU-MERIT). http://www.merit.unu.edu/publications/wppdf/2012/wp2012-041.pdf (17.11.2016).

Niu, X. (2008). Theoretical and practical review of capital structure and its determinants. International Journal of Business and Management, 3(3), 133-139.

Ramaratnam, M.S., \& Jayaraman, R. (2013). Determinants of capital structure with special reference to Indian pharmaceutical sector: Panel data analysis. Journal of Commerce and Accounting Research, 2(4), 45-50.

Reed, R.W., \& Ye, H. (2011). Which panel data estimator should i use?. Applied Economics, (45), 985-1000.

Robichek, A.A., \& Myers, S.C. (1966). Problems in the theory of optimal capital structure. Journal of Financial and Quantitative Analysis, 1(2), 1-35.

Sarlija, H., \& Harc, M. (2012). The impact of liquidity on the capital structure. A case study of Croatian firms. Business Systems Research, 3(1), 30-36.

Sayılgan, G., Karabacak, H., \& Küçükkocaoğlu, G. (2006). The firm-specific determinants of corporate capital structure: Evidence from Turkish panel data. Investment Management and Financial Innovations, 3(3), 125-139.

Scott, S.H. (1976). A theory of optimal capital structure. Bell Journal of Economics, 7(1), 33-54.

Serrasqueiro, Z.S., Armada, M.R., \& Nunes, P.M. (2011). Pecking order theory versus trade-off theory: Are service SMEs'capital structure decisions different?. Service Business, 5(4), 381-409.

Sheikh, N.A., \& Wang, Z. (2011). Determinants of capital structure: An empirical study of firms in manufacturing industry of Pakistan. Managerial Finance, 37(2), 117-133.

Song, H. (2005). Capital structure determinants: An empirical study of Swedish companies (CESIS Electronic working paper series No: 25). http://www.diva-portal.org/smash/get/diva2:565199/FULLTEXT01.pdf (2.12.2016).

Swinnen, S., Voordeckers, W., \& Vandemaele, S. (2005). Capital structure in SMEs: Pecking order versus static trade-off, bounded rationality and behavioural principle. http://www.efmaefm.org/OEFMAMEETINGS/EFMA\%20ANNUAL\%20MEETINGS/2005-Milan/papers/250swinnen_paper.pdf (17.12.2016).

Torres-Reyna, O. (2007). Panel data analysis: Fixed and random effects using Stata. https://www.princeton.edu/ otorres/Panel101.pdf (10.12.2016).

Voulgaris, F., Asteriou, D., \& Agiomirgianakis, G. (2002). Capital structure, asset utilization, profitability and growth in the Greek manufacturing sector. Applied Economics, 34(11), 1379-1388.

Wooldridge, J.M. (2012). Introductory econometrics: A modern approach. Ohio: Cengage Learning.

WTO (World Trade Organization). (2015). International trade statistics 2015. Geneva.

Wu, J. (2007). An empirical study of influential factors of debt financing. International Journal of Nonlinear Science, 3(3), 208-212.

Yıldız, M.E., Yalama, A., \& Sevil, G. (2009). Sermaye yapısı teorilerinin geçerliliğinin test edilmesi: Panel veri analizi kullanılarak iMKB-imalat sanayi sektörü üzerinde ampirik bir uygulama. iktisat iş̧letme ve Finans, 24(278), 25-45.

tcmb.gov.tr (Türkiye Cumhuriyet Merkez Bankası)

tuik.gov.tr (Türkiye İstatistik Kurumu) 
This Page Intentionally Left Blank 